\section{Effects of 1-Ethyl-3-(3- Dimethylaminopropyl) Carbodiimide on Adhesion of Posts in Teeth Obturated With Different Sealers}

\author{
Beatriz Serrato Coelho ${ }^{10}$, Flávia Sens Fagundes Tomazinho ${ }^{10}$, Denise Piotto \\ Leonardi $^{1}$, Fabricio Scaini ${ }^{\mathbb{D}}$, Marilisa Carneiro Leão Gabardo ${ }^{1 \mathbb{C}}$, Rafaela \\ Mariana de Lara ${ }^{10}$, Flares Baratto-Filho ${ }^{2}$ (1)
}

\author{
'School of Health Sciences, \\ UP - Universidade Positivo, \\ Curitiba, PR, Brazil \\ ${ }^{2}$ Department of Dentistry, \\ Universidade da Região de \\ Joinville, Joinville, SC, Brazil
}

Correspondence: Flares Baratto-Filho, Rua Paulo Malschitzki, 10, 89219-710 Joinville, SC, Brasil. Tel: +55-47-34619099. e-mail: fbaratto1@gmail.com

\begin{abstract}
The aim of this study was to evaluate the effect of 1-ethyl-3-(3-dimethylaminopropyl) carbodiimide (EDC) on bond strength of fiberglass posts in root canals obturated with different endodontic sealers. Seventy-eight mandibular premolars were obturated with three sealers ( $n=26)$ : Endofill (END), AH Plus (AHP), and Endosequence BC Sealer (EBS). After preparation of the post space, two subgroups were formed according to the cementation of the posts $(n=13)$ : with EDC (EDC), and without EDC (control - CON). The specimens were submitted to a pull-out test, failure mode classification, and root canal surface evaluation by scanning electron microscopy after post displacement. Regarding the bond strength, a significant difference between the EDC and CON subgroups occurred only in the END ( $p=0.001)$. No difference was detected among the CON subgroups $(p=0.339)$. However, among the EDC subgroups, AHP presented significantly higher values (END versus AHP: $p=0.001$; AHP versus EBS: $p=0.016$ ). Upon classification of failure modes, score 1 ( $\geq 50 \%$ of cement) was the most commonly observed, except for the END + EDC. Remains of endodontic sealers and resin cements were found in the cervical third, but without statistical difference $(p=0.269)$, while in the middle third, difference occurred $(p=0.004)$. In conclusion, EDC decreases bond strength when associated with END sealer, without changing the failure mode between the resin cement and fiberglass post. The best performance was observed when EDC was combined with AHP sealer.
\end{abstract}

Key Words: 1-ethyl-3-

(3-dimethylaminopropyl) carbodiimide, root canal filling materials, bond strength

\section{Introduction}

Teeth with endodontic treatment often lose crown structure due to cavities and fractures. Situations like these make restorative treatment difficult, requiring the use of intraradicular posts for better prognosis of endodontic treatment and rehabilitation (1-3). Fiberglass posts are preferred for this purpose because they have low rigidity, elasticity compatible with dentin and form a unit with the root, which reduces the severity of the fracture when it occurs, causing less damage to the remaining dental structure $(1,4,5)$. For the cementation of these posts, the use of resin-based cements is recommended because of their favorable physical properties and adequate biological performance $(6,7)$.

Durability of the adhesion systems is directly affected by the degradation of collagen matrices present in the resin by matrix metalloproteinases (MMP) $(8,9)$. MMP are activated by dentin demineralization and are responsible for the slow hydrolysis of collagen fibers in the hybrid layer of the resin-dentin system (10). To improve the bonding and increase the durability of the resin-dentin system, the inactivation of MMP by synthetic inhibitors is recommended (9-11).

Currently, some studies show an improvement in the adhesive interface with the use of 1-ethyl-3-(3dimethylaminopropyl) carbodiimide (EDC) $(9,11,12)$. EDC is a cross-linking agent that inactivates MMP, increasing the structural and mechanical stability of collagen, thus enhancing the bond strength between resin materials and dentin $(9,13)$. It is generally used in the form of 0.3 M EDC aqueous solution applied for $60 \mathrm{~s}$, between the etching of dentin and the use of the adhesive system. Evidently, EDC does not cause any immediate change in the bond strength. However, in the long run, the increase may reach $50 \%(11,12)$.

Few studies have tested the effect of EDC on fiberglass post cementation $(12,14)$. In these studies, the endodontic sealer used was the same in all groups, and only the resin cement used in post cementation differed $(12,14)$.

It is known that the adhesion between resin cement, root dentin and post can be affected by the type of the endodontic sealer used $(4,15)$. This is because, even with the chemical and mechanical preparation of the space for the intraradicular retainer, the remaining endodontic material stays adhered on the walls of the root canal and inside the dentinal tubules $(3,16)$.

Eugenol-based sealers are widely used in clinical practice for root canals filling. However, its interference in fiber 
posts bond strength is questioned (15). Epoxy resin-based endodontic sealers such as AH Plus (Dentsply Sirona, York, USA) and bioceramics sealers based on calcium silicate, such as Endosequence BC Sealer (Brasseler USA, Savannah, USA) have showed good results in resin cements adhesion $(4,17,18)$.

There is no evidence to suggest that EDC influences the bond strength of fiberglass posts on root dentin in teeth filled with different endodontic sealers. Thus, the aim of our study was to examine whether the use of EDC influences the bond strength of fiberglass posts and resin cements on dentin, when different endodontic sealers were used in root canal filling. The null hypotheses were that (i) the type of endodontic sealer does not influence bond strength on dentin, and (ii) EDC does not alter the bond strength between post, resin cement and root dentin.

\section{Material and Methods}

\section{Sample Selection}

This study was approved by the Institutional Research Ethics Committee (number 2.166.207). The sample size was calculated with a confidence interval of 95\%, 80\% power, and ratio of 1:1. Seventy-eight human mandibular

\section{Specimen Preparation}

The root canal was explored with $\mathrm{K} \# 10$ file (Dentsply Sirona, York, USA) to verify apical foramen patency. The instrumentation consisted of Wave One Gold Large files (\# 45.05) (Dentsply Sirona, York, USA) with a working length of $14 \mathrm{~mm}$. Irrigation during this step was performed with $5.25 \%$ sodium hypochlorite $(\mathrm{NaOCl})$, followed by final irrigation with 17\% ethylenediaminetetraacetic acid (EDTA) activated by EndoActivator (Dentsply Sirona, York, PA, USA), tip 35.04, according to the manufacturer's protocol. Then, a new irrigation was performed with $5.25 \% \mathrm{NaOCl}$ and drying with \# 45 absorbent paper points (Cell Pack, Dentsply Sirona).

Subsequently, the specimens were filled with guttapercha cones (Wave One Large, Dentsply Sirona) and randomly divided into three groups $(n=26)$, according to the sealer used: Endofill (Dentsply Sirona) - END; AH Plus (Dentsply Sirona) - AHP; Endosequence BC Sealer (Brasseler, Savannah, GA, USA) - EBS. The cavities were sealed with glass-ionomer cement (S.S. White, São Cristovão, SP, Brazil). The gutta-percha cones were thermoplasticized with Mc Spadden \# 45 (Dentsply Sirona). All specimens were stored in distilled water at $37{ }^{\circ} \mathrm{C}$ for 7 days.

After this period the specimens were prepared for installation of fiberglass posts, with drill n. 0.5 (Whitepost DC 0.5, FGM Produtos Odontológicos, Joinville, SC, Brazil) with $10 \mathrm{~mm}$ length. The diameter of the different parts (tip, at 3, 6, $9 \mathrm{~mm}$ from the tip) of this drill was $0.65,0.94$, 1.10 , and $1.46 \mathrm{~mm}$, respectively.

Radiographs were taken after preparation to ensure that the post spaces were free of sealing material but with adequate apical remnants. The space was cleaned with 17\% EDTA and dried with absorbent paper points \# 45 (Cell Pack, Dentsply Sirona) (18).

The specimens were then subdivided into EDC and control (CON) subgroups. In the CON subgroups the cementation was done according to the resin cement manufacturer's protocol. In the EDC subgroups, $1 \mathrm{~mL}$ of 0.3 $M$ EDC aqueous solution was applied for $60 \mathrm{~s}$, followed by drying and cementing of the post, also according to the resin cement manufacturer. In the protocol used, resin cement (Dual Set PP, SDI Limited, Bayswater, Australia) was applied on the post surface and the walls of the root canal. The posts were left in position for $30 \mathrm{~s}$, with removal of excess cement and photoactivation for $20 \mathrm{~s}$. The specimens were stored in distilled water at $37{ }^{\circ} \mathrm{C}$ for 30 days.

\section{Pull-Out Test}

The bond strength was assessed by the pull-out test in a universal test machine (EMIC, Instron Brasil Equipamentos Científicos Ltda, São José dos Pinhais, PR, Brazil). A force of $0.5 \mathrm{~mm} / \mathrm{min}$ was applied to longitudinally draw the post in the coronal direction until its displacement. At the moment of displacement, the maximum force in $\mathrm{N}$ was recorded (6).

\section{Classification of Union Failure Modes Of Post/Resin Cement}

The posts were analyzed under a stereomicroscope with $10.5 \times$ magnification to determine the amount of remaining cement. According to the percentage of cement on the post surface, they were classified as score 1 ( $\geq 50 \%$ of cement) and score 2 ( $<50 \%$ of cement) (Fig. 1) (19).

\section{Analysis of the Root Canal Surface}

After the displacement of the posts, the roots were sectioned longitudinally, and the surface of the canal was analyzed in the middle and coronal thirds through Energy Dispersive X-Ray Fluorescence Spectrometry (EX94410T1L11, JEOL Ltd, Tokyo, Japan) using a scanning electron microscope (6010LA, JEOL Ltd, Tokyo, Japan). For better analysis, the samples were dehydrated in an incubator at $50^{\circ} \mathrm{C}$ for $24 \mathrm{~h}$ and then gold sputtered (Denton Vacuum Desk IV Standard, Moorestown, NJ, USA). In each third, every material found inside the canal was marked to be analyzed for determining their composition (Fig. 2). With 
a comparation between the composition of these materials and the individual analysis of the sealers, the root canal surface was classified according the material found.

To obtain the chemical composition pattern of the endodontic cements and the resin cement, a sample from each cement was analyzed individually before the analyses of the specimens.

The data were analyzed and classified as follows: (0) absence of resin cement or endodontic sealer; (1) presence of endodontic sealer; (2) presence of resin cement; and (3) presence of resin cement and endodontic sealer. Figure 3 illustrates this classification.

\section{Statistical Analysis}

Normality of data values was evaluated by the ShapiroWilk test. The analysis of the interaction was performed by the analysis of variance model (ANOVA). Considering that a significant interaction was detected, one-way ANOVA and
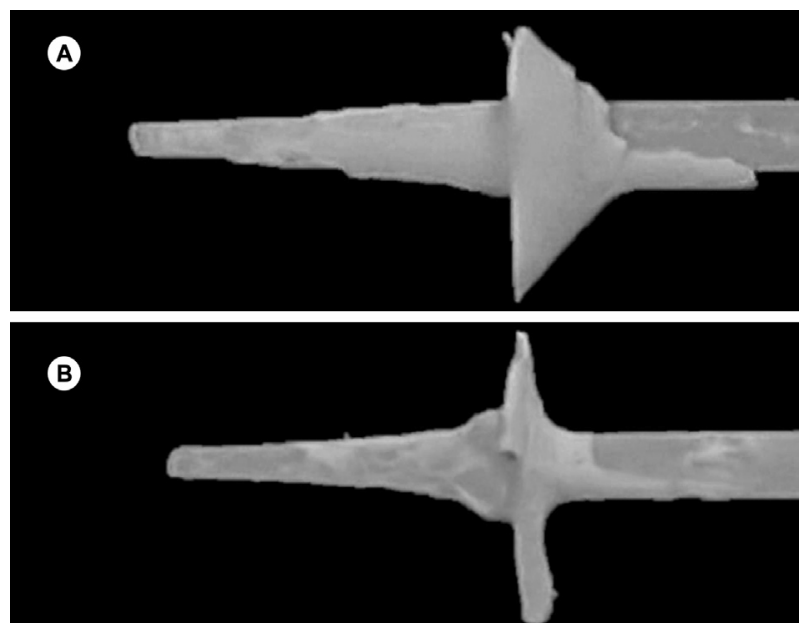

Figure 1. Stereomicroscope images of the posts to illustrate the scores of the classification employed to evaluate the failure modes with $10.5 \times$ magnification. Note: A: score $1: \geq 50 \%$ of resin cement on the post surface; B: score $2:<50 \%$ of resin cement on the post surface.
Student's t test for independent samples were used for the comparison between groups and subgroups. Chi-square test was used for the analysis of differences between groups in the thirds regarding the failure mode and evaluation of the root canal surface. Pvalues $<0.05$ indicated statistically significant difference. The data were analyzed using the software SPSS v. $21.0\left(\right.$ IBM $^{\circledR}$ SPSS ${ }^{\circledR}$, Armonk, NY, USA).

\section{Results}

Four specimens were lost during the pull-out test, one of each of these groups: AHP, AHP + EDC, EBS, and EBS + EDC.

\section{Bond Strength}

There was no statistically significant difference in dentin/cement bond strength in the AHP $(p=0.644)$ and EBS ( $p=0.433$ ) groups when EDC was used, compared with the corresponding CON subgroups. In the END group, a statistically significant difference was detected between

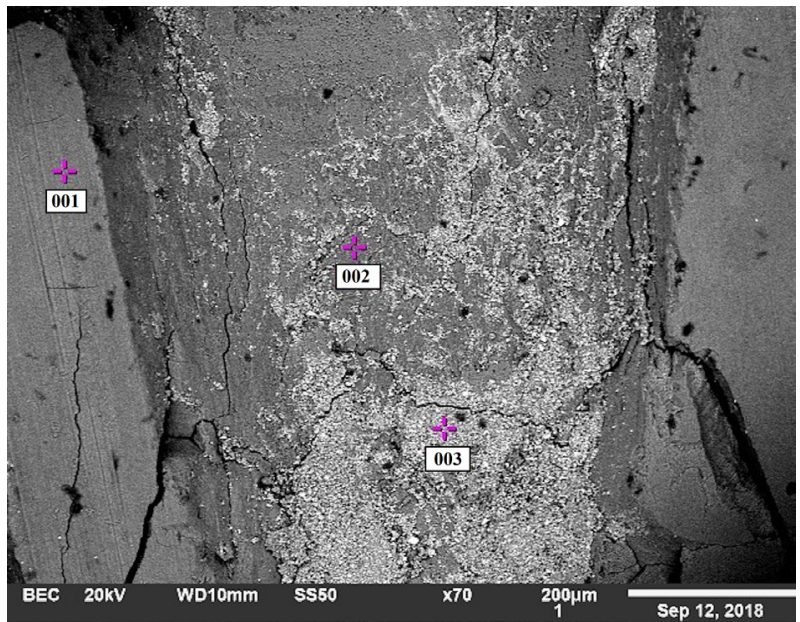

Figure 2. Punctual marking of each material found within the canal for analysis of its composition. Image obtained by a scanning electron microscopy with a 70x magnification. Note: 001 - radicular dentin 002 - endodontic sealer; 003 - resin cement.
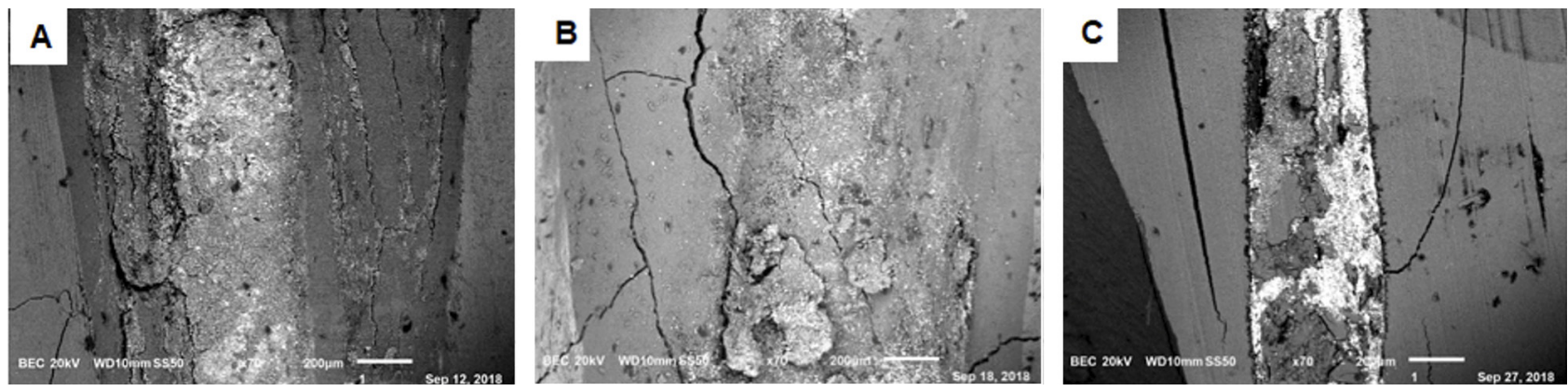

Figure 3. Illustrative image of the of the root canal surface analyzed by scores. Image obtained by a scanning electron microscopy with a 70x magnification. A: presence of endodontic sealer; B: presence of resin cement; C: presence of resin cement and endodontic sealer. 
the EDC and CON subgroups. In particular, EDC application reduced bond strength $(\mathrm{p}=0.001)$ (Table 1 ).

Comparison among the CON subgroups of the different sealer groups showed no statistically significant difference $(p=0.339)$. Among the EDC subgroups, AHP exhibited the highest bond strength values (END versus AHP: $p=0.001$, AHP versus EBS: $p=0.016$ ) (Table 1 ).

\section{Classification of Failure Modes of Post/Resin Cement}

Statistical difference occurred in this analysis $(p=0.019)$, with the score 1 being the most frequently observed, except for the END + EDC, in which score 2 was more frequent. Also, regarding score 2, the END + EDC group differed from the others (Table 2).

\section{Analysis of the Root Canal Surface}

In the cervical third no statistical difference was found $(p=0.269)$. However, in the middle, statistical difference occurred $(p=0.004)$, and the results are shown in Table

Table 1. Results (mean \pm standard deviation) of bond strength $(\mathrm{N})$ between post, resin cement, and dentin

\begin{tabular}{|c|c|c|}
\hline Sealers & Control group & EDC group \\
\hline Endofill & $57.1( \pm 19.3)$ Аа & $31.8( \pm 10.5)^{\mathrm{Ba}}$ \\
\hline AH Plus & $49.9( \pm 24.1)$ Аа & $53.6( \pm 16.0)$ Aa \\
\hline Endosequence BC Sealer & $44.7( \pm 20.2)$ Аa & $38.7( \pm 17.2)$ Aa \\
\hline
\end{tabular}

Different capital letters indicate statistically significant differences among rows. Different lowercase letters indicate statistically difference between columns. EDC: 1-ethyl-3-(3-dimethylaminopropyl) carbodiimide.

Table 2. Results [n (\%)] of the analysis between groups, according to the percentage of resin cement on the post surface

\begin{tabular}{lccccccc}
\hline Score & END & END + EDC & AHP & AHP+ EDC & EBS & EBS + EDC & Total \\
\hline 1 & $10^{\mathrm{a}}(76.9)$ & $5^{\mathrm{b}}(38.5)$ & $1^{\mathrm{a}}(91.7)$ & $10^{\mathrm{a}}(83.3)$ & $11^{\mathrm{a}}(91.7)$ & $9^{\mathrm{a}, \mathrm{b}}(75.0)$ & $56(75.7)$ \\
2 & $3^{\mathrm{a}}(23.1)$ & $8^{\mathrm{b}}(61.5)$ & $1^{\mathrm{a}}(8.3)$ & $2^{\mathrm{a}}(16.7)$ & $1^{\mathrm{a}}(8.3)$ & $3^{\mathrm{a}, \mathrm{b}}(25.0)$ & $18(24.3)$ \\
\hline
\end{tabular}

Different lowercase letters indicate statistically significant difference between rows. Chi-square test $(\mathrm{p}<0.05)$. Score 1: $\geq 50 \%$ of cement; Score $2:<50 \%$ of cement.

Table 3. Results of the analysis between groups, in middle third, according to the scores attributed to the amount and type of material remaining in the wall of the root canal

\begin{tabular}{lccccccc}
\hline Score & END & END + EDC & AHP & AHP+ EDC & EBS & EBS + EDC & Total \\
\hline 0 & $0^{\mathrm{a}}(0.0)$ & $0^{\mathrm{a}}(0.0)$ & $2^{\mathrm{a}, \mathrm{b}}(15.4)$ & $1^{\mathrm{a}, \mathrm{b}}(8.3)$ & $4^{\mathrm{b}}(30.8)$ & $1^{\mathrm{a}, \mathrm{b}}(8.3)$ & $8(10.5)$ \\
1 & $1^{\mathrm{a}, \mathrm{b}}(7.7)$ & $2^{\mathrm{a}, \mathrm{b}, \mathrm{c}}(15.4)$ & $0^{\mathrm{b}}(0.0)$ & $4^{\mathrm{a}, \mathrm{c}}(33.3)$ & $2^{\mathrm{a}, \mathrm{b}, \mathrm{c}}(15.4)$ & $6^{\mathrm{c}}(50.0)$ & $15(19.7)$ \\
2 & $1^{\mathrm{a}, \mathrm{b}, \mathrm{c}, \mathrm{d}}(7.7)$ & $5^{\mathrm{c}, \mathrm{d}}(38.5)$ & $5^{\mathrm{b}, \mathrm{d}}(38.5)$ & $1^{\mathrm{a}, \mathrm{b}, \mathrm{c}, \mathrm{d}}(8.3)$ & $0^{\mathrm{a}}(0.0)$ & $1^{\mathrm{a}, \mathrm{b}, \mathrm{c}, \mathrm{d}}(8.3)$ & $13(17.1)$ \\
3 & $1^{\mathrm{a}}(84.6)$ & $6^{\mathrm{b}}(46.2)$ & $6^{\mathrm{b}}(46.2)$ & $6^{\mathrm{a}, \mathrm{b}}(50.0)$ & $7^{\mathrm{a}, \mathrm{b}}(53.8)$ & $4^{\mathrm{b}}(33.3)$ & $40(52.6)$ \\
\hline
\end{tabular}

Note: Different lowercase letters indicate statistically significant difference between rows. Score 0: absence of material Qui-square test $(\mathrm{p}<0.05)$; Score 1: presence of endodontic sealer; Score 2: presence of resin cement; Score 3: presence of endodontic sealer and resin cement.
3. The presence of endodontic sealer was lower in END groups - with or without EDC - when compared with EBS group. The use of EDC does not show difference between subgroups for the presence of only resin cement in root canal surface. This was different when resin cement and endodontic sealer was observed in root canal walls. The frequency of this situation was lower when EDC was used with END, compared with END.

\section{Discussion} sealer does not influence bond strength on dentin, and (ii) that EDC does not alter the bond strength between post, resin cement, and dentin were rejected.

The initial number of samples was 78, with 13 The traction in the pullthe post

: When the results of bond strength of post/resin cement are analyzed together, it was confirmed some interaction between AHP and EDC, which allowed greater bond strength between root dentin, resin cement, and fiberglass post, since most of the specimens in the AHP group had sealer remains in the root canal wall after endodontic treatment. As the frequency of walls with sealer remnants was similar between the groups, and there was a significant difference in the bond strength results, it is possible that EDC interacted with the sealer, and not only with dentin.

Wh e $\mathrm{n} \quad \mathrm{END}$ sealer was used, this interaction was negative. Indeed, a worsening in the bond strength between root dentin, resin cement, and fiberglass post with the use of EDC was 
detected only in the END group. The absence of significant differences in the other groups may be a consequence of sample storage time (15). Regarding the period of 30 days, selected as critical, it is found in the literature that the activity of EDC in inhibit dentinal gelatinases is already present after $24 \mathrm{~h}(9,13)$, and this effect decreases over time (13). Previous studies, that evaluated different times of EDC pre-treatment in bond strenght, had as immediate time $24 \mathrm{~h}$ (19). After 30 days, the EDC is now acting and, considering that the greater manipulation of the post occurs in this period, it was considered valid to test this interval, in which great manipulation of the post occurs, with preparation of remnants, molding and cementation of prosthetic pieces.

Without the use of synthetic inhibitor EDC there was no difference in bond strength between the sealers used. Previous studies also demonstrated that the sealer does not alter the bond strength $(21,22)$. However, the results reported in the literature are variable $(4,17,18)$. Moreover, the mechanical test used in this study was different from previous studies. The pull-out is a mechanical test with high clinical relevance (23). The results obtained may be different from those in the push-out test, since it may overestimate the results by evaluating only small areas at a time (24). In addition, due to the mechanical test we used, the classification of the failure modes of the union was made based on the amount of material present on the entire surface of the post. Teeth with a large amount of cement on their surface indicate adhesive failure between cement and dentin (23).

The results of this study showed that lower bond strength could not be related to a worse bond strength of resin cement to dentin. This could be observed in the END group, in which there was a decrease in bond strength with EDC. However, in the same group a higher percentage of posts was classified as score 2 ( $<50 \%$ of cement). This indicates that the largest failure occurred between the post and resin cement, without the involvement of dentin. This result corroborates the study by Vilas-Boas et al. (17). However, it is important to note that failure mode analysis is a complementary test. This data may indicate that other factors are also related with bond strength, such as the adhesion of the cement to the fiberglass post (17). For this reason, the root surface was also analyzed.

In the classification of the remaining material on the root canal wall, most of the samples were classified as mixed, because there were endodontic sealer and resin cement adhered on the surface. Only the CON subgroup of the AHP group showed the majority of root surfaces covered with resin cement. It should be noted, however, that we cannot rule out the presence of underlying endodontic sealer in cases in which only resin cement was detected. Therefore, the presence of endodontic sealer was evident in almost all samples analyzed. This is corroborated by previous studies reporting that, even after the preparation of the space that will receive the post, there are endodontic sealer remnants on the walls and in the dentinal tubules $(3,16)$. The use of EDC does not influence the presence of sealer, since its use does not aim at the removal of this material from the canal wall, but rather at the biomodification of the dentin collagen structure (25).

Only in the middle third of the root completely clean walls were detected after the displacement of the post. This can be explained by the larger diameter of the preparation drill in this portion when compared with the endodontic instrument which means that there is removal of the dentin wall and not only of the obturator material. It should be noted that samples with any amount of sealer were classified as having sealer. Only completely clean samples were considered as not having any material.

The use of EDC is generally indicated after acid etching of dentin, due to its MMPs inactivation action (10). When self-adhesive cement is used, it was believed that EDC could be underutilized because the acid attack is not performed separately. Previous literature proved that EDC had a positive effect on the bond strength of the post on the wall of the root canal, even when selfadhesive cement is used (19).

Despite the limitations of this study, it can be concluded that using EDC alters the bond strength among root dentin, resin cement, and fiberglass post. There is a decrease in bond strength when the root canal is filled with END sealer and an increase when filled with AHP.

\section{Resumo}

0 objetivo deste estudo foi avaliar o efeito da 1-etil-3-(3-dimetilaminopropil) carbodiimida (EDC) na resistência de união de pinos de fibra de vidro em canais radiculares obturados com diferentes cimentos endodônticos. Setenta e oito pré-molares inferiores foram obturados com três cimentos endodônticos ( $n=26)$ : Endofill (END), AH Plus (AHP) e Endosequence BC Sealer (EBS). Após o preparo do espaço para pino, dois subgrupos formaram-se conforme a cimentação dos pinos $(n=13)$ : com EDC e sem EDC (controle - CON). Os espécimes foram submetidos ao teste pull-out, classificação do modo de falha e avaliação da superfície do canal radicular por microscopia eletrônica de varredura após o deslocamento. Quanto à força de resistência de união, uma diferença estatisticamente significativa ocorreu entre os subgrupos EDC e CON apenas no END $(p=0,001)$. Não foi detectada diferença entre os subgrupos $\operatorname{CON}(p=0,339)$. Contudo, no subgrupo EDC, o AHP apresentou maiores valores (END versus $A H P: p=0,001$; AHP versus EBS: $p=0,016$ ). Acerca da classificação dos modos de falha, 0 escore 1 ( $\geq 50 \%$ de cimento) foi o mais comumente observado, exceto para END + EDC. Restos de cimentos endodônticos e cimentos resinosos foram encontrados no terço cervical, mas sem diferença estatística $(p=0,269)$, enquanto no terço médio, houve diferença $(p=0,004)$. Em conclusão, 0 EDC diminui a resistência de união quando associado ao cimento END, sem alterar o modo de falha entre o cimento resinoso e o pino de fibra de vidro. 0 melhor desempenho foi observado quanto o EDC foi usado com o cimento AHP. 


\section{References}

1. Bateman $G$, Ricketts DN, Saunders WP. Fiber-based post systems: a review. Br Dent J 2003; 195: 43-48; discussion 37.

2. Morgano SM. Restoration of pulpless teeth: application of traditional principles in present and future contexts. J Prosthet Dent 1996;75:375380.

3. Serafino C, Gallina G, Cumbo E, Ferrari M. Surface debris of canal walls after post space preparation in endodontically treated teeth: a scanning electron microscopic study. Oral Surg Oral Med Oral Pathol Oral Radiol Endod 2004;97:381-387.

4. Forough Reyhani M, Ghasemi N, Rahimi S, Milano AS, Omrani E. Effect of different endodontic sealers on the push-out bond strength of fiber posts. Iran Endod J 2016;11:119-123.

5. Hayashi M, Takahashi Y, Imazato S, Ebisu S. Fracture resistance of pulpless teeth restored with post-cores and crowns. Dent Mater 2006;22:477-485.

6. Aleisa K, Al-Dwairi ZN, Alsubait SA, Morgano SM. Pull-out retentive strength of fiber posts cemented at different times in canals obturated with a eugenol-based sealer. J Prosthet Dent 2016;116:85-90.

7. Lee KW, Williams MC, Camps JJ, Pashley DH. Adhesion of endodontic sealers to dentine and gutta-percha. J Endod 2002;28:684-688.

8. Breschi L, Mazzoni A, Ruggeri A, Cadenaro M, Di Lenarda R, De Stefano Dorigo E. Dental adhesion review: aging and stability of the bonded interface. Dent Mater 2008;24:90-101.

9. Mazzoni A, Apolonio FM, Saboia VP, Santi S, Angeloni V, Checchi V, et al. Carbodiimide inactivation of MMPs and effect on dentin bonding. J Dent Res 2014;93:263-268.

10. Breschi $L$, Martin P, Mazzoni $A$, Nato $F$, Carrilho $M$, Tjäderhane $L$, et al. Use of a specific MMP inhibitor (Galardin) for preservation of hybrid layer. Dent Mater 2010;26:571-578.

11. Scheffel D, Delgado CC, Soares DG, Basso FG, de Souza Costa CA, Pashley $\mathrm{DH}$, et al. Increased durability of resin-dentin bonds following cross-linking treatment. Oper Dent 2015;40:533-539.

12. Shafiei F, Yousefipour B, Bassir MM. Effect of carbodiimide on bonding durability of adhesive-cemented fiber posts in root canals. Oper Dent 2016;41:432-440.

13. Mazzoni A, Angeloni V, Sartori N, Duarte S Jr, Maravic T, Tjäderhane $L$, et al. Substantivity of carbodiimide inhibition on dentinal enzyme activity over time. J Dent Res 2017;96:902-908.

14. Alonso JRL, Basso FG, Scheffel DLS, de Souza-Costa CA, Hebling J. Effect of crosslinkers on bond strength stability of fiber posts to root canal dentin and in situ proteolytic activity. J Prosthet Dent 2018;119:494. e1-494.e9.
15. Altmann AS, Leitune VC, Collares FM. Influence of eugenol-based sealers on push-out bond strength of fiber post luted with resin cement: systematic review and meta-analysis. J Endod 2015;41:14181423.

16. Teoh $Y$ Y, Walsh $\sqcup$. Residual endodontic filling material after post space preparation: a confocal microscopic study. Materials 2017;10.pii:E1333.

17. Vilas-Boas DA, Grazziotin-Soares R, Ardenghi DM, Bauer J, de Souza P0, de Miranda Candeiro GT, et al. Effect of different endodontic sealers and time of cementation on push-out bond strength of fiber posts. Clin Oral Investig 2018;22:1403-1409.

18. Bohrer TC, Fontana PE, Wandscher VF, Morari VHC, Dos Santos SS, Valandro LF, et al. Endodontic sealers affect the bond strength of fiber posts and the degree of conversion of two resin cements. J Adhes Dent 2018;20:165-172.

19. Singh S, Nagpal R, Tyagi SP, Manuja N. Effect of EDTA conditioning and carbodiimide pretreatment on the bonding performance of all-in-one self-etch adhesives. Int J Dent 2015;2015:141890.

20. Sonntag D, Ritter A, Burkhart A, Fischer J, Mondrzyk A, Ritter H. Experimental amine-epoxide sealer: a physicochemical study in comparison with AH Plus and EasySeal. Int Endod J 2015;48:747-756.

21. Ruiz L, Gomes GM, Bittencourt B, da Silva FR, Gomes OMM, Chidoski Filho Jc, et al. Effect of root canal sealers on bond strength of fiber posts to root dentin cemented after one week or six months. Iran Endod J 2018;13:54-60.

22. Santana FR, Soares CJ, Ferreira JM, Valdivi ADCM, de Souza JB, Estrela C. Effect of root canal sealer and artificial accelerated aging on fibreglass post bond strength to intraradicular dentin. J Clin Exp Dent 2014;6:e350-356.

23. Mushashe AM, Amaral RO, Rezende CE, Baratto Filho F, Cunha LF, Gonzaga CC. Effect of sonic vibrations on bond strength of fiberglass posts bonded to root dentin. Braz Dent J 2017;28:30-34.

24. Giachetti L, Grandini S, Calamai P, Fantini G, Scaminaci Russo D. Translucent fiber post cementation using light- and dual-curing adhesive techniques and a self-adhesive material: push-out test. J Dent 2009;37:638-642.

25. Bedran-Russo AK, Pauli GF, Chen SN, McAlpine J, Castellan CS, Phansalkar RS, et al. Dentin biomodification: strategies, renewable resources and clinical applications. Dent Mater 2014;30:62-76.

Received December 24, 2019

Accepted February 10, 2020 